\title{
CONTRIBUIÇÕES DA NEUROEDUCAÇÃO PARA A PRÁTICA PEDAGÓGICA
}

\author{
Amanda dos Santos Brandão' \\ Susana Gakyia Caliatto²
}

\section{RESUMO}

Os avanços da Neurociência Cognitiva, sobre os processos de aprendizagem, têm levado pesquisadores a perceberem a importância da proximidade com a área educacional, bem como a real necessidade de se desenvolverem pesquisas e práticas sistematizadas sobre 0 assunto, enfatizando a relação ensinoaprendizagem. O presente artigo teve como objetivo levantar na literatura das neurociências alguns conhecimentos teóricos da neuroeducação para contextualizar e fundamentar as aplicações educacionais e pedagógicas de uma prática educativa. Para o desenvolvimento deste estudo, foi observada uma experiência de prática pedagógica, em uma escola de ensino não formal, em uma cidade do sul de Minas Gerais. A discussão em torno da possibilidade de fundamentar as aplicações educativas e pedagógicas apontam para uma coerência entre as afirmativas das descobertas atuais, os resultados de pesquisa em neuroeducação e a experiência relatada.

Palavras-chave: Aprendizagem. Neuroeducação. Prática Pedagógica.

\section{CONTRIBUTIONS OF NEUROEDUCATION TO PEDAGOGICAL PRACTICE}

\begin{abstract}
The advances of Cognitive Neuroscience, about the learning processes, make the researchers see the importance of approaching the neuroscience and educational areas. And see the need to develop systematized research and practices on the subject emphasizing the teaching-learning relationship. This article aims to research the publication of neurosciences, the theoretical knowledge of neuroeducation to contextualize and to base the educational and pedagogical applications of an educational practice. For the development of the study was an experience of pedagogical practice of a non-formal school in a city of Minas Gerais / Brazil was described. It is possible to discuss and provide theoretical basis for the educational applications and pedagogical practices of the experience observed through the current findings and results of research in neuroeducation.
\end{abstract}

Keywords: Learning. Neuroeducation. Pedagogical practice.

\footnotetext{
1 Pedagoga pela Universidade do Vale do Sapucaí (Univás/MG). ORCID iD: https://orcid.org/0000-0002-5866-1843. E-mail: amanda_santos_brandao@hotmail.com

2 Professora Doutora do Mestrado em Educação da Universidade do Vale do Sapucaí (Univás/MG). ORCID iD: https://orcid.org/0000-0002-8688-653X. E-mail: caliatto.sgc@gmail.com
} 


\section{CONTRIBUCIONES DE NEUROEDUCACIÓN A LA PRÁCTICA PEDAGÓGICA}

\section{RESUMEN}

Los avances de la Neurociencia Cognitiva, sobre los procesos de aprendizaje, llevaron a los investigadores a percibir la importancia de la proximidad con el área educativa, y la necesidad de desarrollar investigaciones y prácticas sistematizadas sobre el tema, enfatizando la relación enseñanza-aprendizaje. El presente artículo tuvo como objetivo relevar en la literatura de las neurociencias algunos conocimientos teóricos de la neuroeducación para contextualizar y fundamentar las aplicaciones educativas y pedagógicas de una práctica educativa. Para el desarrollo del estudio se realizó la observación de una experiencia de práctica pedagógica en uma escuela de enseñanza no formal, en una ciudad del Sur de Minas Gerais / Brasil. La discusión en torno a la posibilidad de dar fundamento teórico para a las aplicaciones educativas y pedagógicas se dirige a la coherencia entre las afirmacionesde los descubrimientos actuales, de los resultados de investigación en neuroeducación y de la experiencia relatada.

Palabras clave: Aprendizaje. Neuroeducación. Práctica pedagógica.

\section{INTRODUÇÃO: A NEUROCIÊNCIA COGNITIVA}

Cognição é um termo de difícil definição, geralmente relacionado a desencadeamentos processuais e funcionais do cérebro e ao desenvolvimento da aprendizagem. Tem sido apontado, em estudos que se propõem a desvelar os conteúdos sobre o desenvolvimento da inteligência humana, seja entre os teóricos clássicos como Piaget (1973) e Flavell (1999) ou mais recentemente em Blakemore e Firth (2000) e Leme (2011), que esse termo se refere ao domínio mental incluindo as emoções.

A neurociência cognitiva é considerada recente na história das ciências cognitivas, sendo o termo utilizado com maior expressão, a partir da década de 1970 (HAEFFNER; GUIMARÃES, 2015; SILVA; MORINO, 2012). Decisivamente, os estudos nesta área parecem promissores e proporcionalmente valiosos, por estarem diretamente centrados no desenvolvimento cognitivo e contribuírem para evolução da pesquisa sobre os processos de aquisição de conhecimento humano e a aprendizagem (HASSE; PINHEIRO-CHAGAS; ARANTES, 2009). Pelo que se acredita que são uma importante contribuição para área educacional e da formação de professores. 
O objeto material de estudo das neurociências cognitivas é o cérebro e suas propriedades funcionais, neurológicas e psicológicas, bem como as de cunho social, provenientes das relações humanas na sociedade. Imaterialmente, a neurociência cognitiva conjectura sobre a aprendizagem humana. A aprendizagem pode ser definida como um processo de mudança individual, produzido pela experiência e com caráter adaptativo. Ela ocorre na maioria dos organismos e espécies que estão em constante modificação e respondendo às experiencias no ambiente (LEME, 2011).

No conjunto de saberes das neurociências cognitivas está o que já se descobriu sobre o Sistema Nervoso Central (SNC), local onde acontecem não só os pensamentos, mas, também as emoções, comportamentos e a mobilidade. Consequentemente, é a partir dos conhecimentos dessa área que surgem avanços e melhorias para a qualidade de vida das pessoas, por meio da disponibilidade de tratamentos efetivos para variados distúrbios neurológicos, mentais e físicos. Nesse sentido, a neurociência vem contribuindo significativamente para o desenvolvimento de soluções de diversos transtornos e doenças, incluindo problemas educacionais (SILVA; MORINO, 2012).

Silva e Morino (2012) apontam ainda, que conhecer as estruturas do sistema nervoso como o cérebro, cerebelo, neurônios, hemisférios, lobos, entre outros e as suas funções como a atenção, memória, emoção, expressão, motivação, sono, etc. pode ser fundamental para o trabalho em múltiplas áreas e não apenas a médica ou psicológica. Portanto, é um conhecimento importante a quem deseja e necessita compreender modelos de aprendizagem.

O sistema nervoso central (SNC) é a principal rede de comunicação e controle do corpo. Os sinais elétricos são transmitidos e retransmitidos constantemente, por meio de complexas redes de neurônios, a partir do cérebro aos órgãos, membros e partes do corpo e vice-versa. Nessa comunicação composta de circuitos neuronais ocorre o processamento das informações, antecipado pela entrada das sensações e percepções que resultam em comportamentos de saída (SILVA; MORINO, 2012).

Revista Exitus, Santarém/PA, Vol. 9, №3, P. 521 - 547, JUL/SET 2019. 
De forma sintética, o processamento da informação é composto pela recepção, análise e integração de conhecimentos ou aprendizagens armazenadas na memória. O neurônio é a unidade básica do processamento das informações do SNC e consiste em um corpo celular em que, em sua estrutura assemelha-se às demais células, mas, tem peculiaridades próprias de sua natureza que é sinalizadora (MUSSAK, 1999; SILVA; MORINO, 2012).

A capacidade do neurônio é conferida por sua membrana plasmática, uma estrutura especializada na produção e na propagação de impulsos elétricos. Sua característica mais importante é o impulso nervoso que age desde a mais elementar das formas, que consiste em uma partícula química que se movimenta pela membrana externa da célula, até as sinapses que são locais de comunicação, em que os neurônios transmitem entre si os impulsos nervosos (MUSSAK, 1999). O autor ainda acrescenta as implicações das atividades neuronais para o funcionamento de habilidades humanas:

O aumento das sinapses melhora o raciocínio e a memória, pois há um incremento da velocidade da transmissão entre neurônios e da ação sobre eles dos neurotransmissores, substâncias químicas produzidas pelo próprio cérebro e que regulam suas funções, o que tem reflexos na capacidade de análise e armazenamento de informações (MUSSAK, 1999, p. 35-36).

Leite (2011) sintetiza que o cérebro humano é um órgão permeado de segredos que ainda precisam ser acessados pela ciência, para 0 conhecimento de todos. Os 86 bilhões de células nervosas, ou os neurônios, comunicam-se entre si por meio de impulsos eletroquímicos para produzir atividades como os pensamentos, sentimentos, dor, emoções, sonhos, movimentos e muitas outras funções mentais e físicas.

Desvendar os processos do cérebro, aliando-os a outras descobertas científicas tem proporcionado novas áreas de estudo e ampliação dos conhecimentos científicos sobre a aprendizagem. Leite (2011) prevê que a plasticidade, característica do cérebro de se remodelar em função das 
experiências do sujeito, é um dos conhecimentos mais importantes a ser levado em consideração, na aprendizagem e, portanto, pela área educacional.

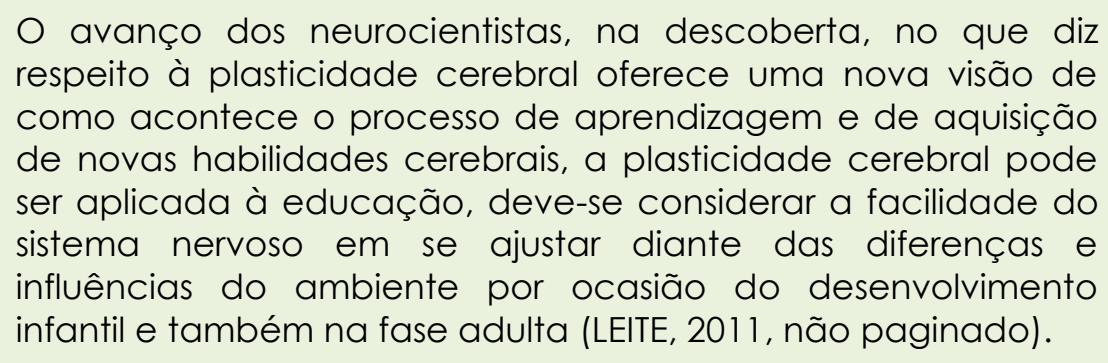

A inserção dos avanços da neurociência nos processos educacionais tem levado pesquisadores a perceberem a importância dessa proximidade das áreas, bem como a real necessidade de se desenvolverem pesquisas e práticas sistematizadas sobre o assunto, enfatizando a relação ensinoaprendizagem (BARRIOS-TAO, 2016). Nesse contexto, encontra-se a pesquisa de Haeffner e Guimarães (2015), que desenvolveram uma análise da produção científica na área de Neurociências e do Comportamento relacionado à Educação, que considera dados mundiais. Os pesquisadores constataram um crescimento da temática em número de artigos publicados, destacando que, para o Brasil, no período de 1990 a 2014, encontraram 482 artigos publicados. Esses resultados dentro do país indicam uma reconhecida cooperação entre os grupos de pesquisa das instituições universitárias do país, nessa área.

Pode-se compreender que da expansão da neurociência cognitiva para o campo educacional emerge a ciência neuroeducacional. Os estudos de Bartoszeck (2006), Zaro et al (2010), Puebla e Talma (2011), BarriosTao (2016) evidenciam conteúdos sobre a relevância e desenvolvimento da Neuroeducação. Em geral, afirmam que essa nova ciência pode ser considerada um campo multidisciplinar de conhecimento e de atuação do profissional da educação.

O desenvolvimento e aprimoramento da neuroeducação merece destaque para a melhoria da qualidade em docência e pesquisa no campo educacional. Barrios-Tao (2016) destaca que "resultados de investigaciones

Revista Exitus, Santarém/PA, Vol. 9, №3, p. 521 - 547, JUL/SET 2019. 
neurocientíficas se convierten en una posibilidad para contribuir al mejoramiento de procesos educativos y a la solución de problemas relacionados con el aprendizaje" (p. 395).

Especificamente a respeito da formação de professores, os trabalhos de Silva e Morino (2012) e Vieira (2012) dão especial atenção para a necessidade de se empregar as contribuições das neurociências aos entendimentos dos professores por meio da qualificação destes, para a prática pedagógica, seja em formações contínuas ou na formação inicial. Silva e Morino (2012) discorrem sobre a importância do conhecimento e aplicação dos dados dos estudos sobre o cérebro, para a formação de professores com base em trabalhos de pesquisadores e docentes.

No estudo de Silva e Morino (2012) destaca-se a tecnologia das imagens que promove uma relação entre a neurociência cognitiva e os processos cognitivos ao lançar luzes sobre a natureza da aprendizagem, conteúdo de responsabilidade dos professores, nas escolas. Nesse contexto, os conhecimentos oferecidos pelas neuroimagens, a exemplo da Imagem por Ressonância Magnética Funcional (FMRI), podem ajudar no desenvolvimento de diagnóstico de processos cognitivos e levar o professor a desenvolver estratégias pedagógicas para lidar com disfunções neurológicas intervenientes na aquisição de aprendizagens. Essa expansão do conhecimento cognitivo contribui para uma educação diferenciada, na qual, a averiguação das dificuldades de aprendizagem melhora a compreensão das diferenças individuais.

Outro aspecto levantado por Silva e Morino (2012) é consideração de que as neurociências permitem aos professores o conhecimento das ciências computacionais, que podem ser a chave para o desenvolvimento de softwares que ajudem no domínio das aprendizagens escolares, concluindo que:

Portanto, as implicações do conhecimento e a aplicação dos dados dos estudos sobre o cérebro na formação de professores é de grande importância aos currículos de formação docente, como indicador de ciência, tecnologia e visão futurista no 
panorama das Ciências da Educação, pois, neurociência educacional (NE) logo será uma realidade na formação de professores, e isto será um desafio para todos os envolvidos no processo de ensino-aprendizagem (SILVA; MORINO, 2012, p. 4950).

O trabalho de Vieira (2012) busca enumerar aspectos que podem contribuir para a formação dos professores e cooperar com a aproximação destes com os neurocientistas, contudo, advertem que não se pode abordar neurociências em apenas um momento e sim abordá-la por toda a prática docente a fim de inovar as discussões e descartar saberes pedagógicos que possam ser superados. O autor relata que alguns trabalhos de pesquisa dessa área projetam nas neurociências, o potencial de aproximar aspectos biológicos, sociais e culturais conjugados nos processos de formação de professores.

O levantamento de Vieira (2012) aponta contribuições das neurociências em relação aos saberes sobre capacidades cognitivas para o planejamento do ensino específico e a promoção da integração de áreas cerebrais, como ocorre, por exemplo, na aprendizagem da matemática, por meio do ensino de música; o conhecimento sobre os processos de fluência em leitura e suas relações neurofisiológicas ou de geografia cerebral; informações que discorrem sobre as peculiaridades na educação de pessoas com necessidade especiais, destacadamente no autismo e na gagueira; o reconhecimento das relações entre emoção e cognição.

Por fim, as dificuldades e transtornos de aprendizagem não são esquecidas no que tange às relações com 0 conhecimento das neurociências verificadas pelos testes psicométricos. As indicações de Vieira (2012) se encerram com uma importante ênfase ao estímulo da inclusão de saberes das neurociências na área educacional:

A espera de profissionais específicos capazes de construir pontes entre educação e neurociências, não deve configurar obstáculo para que se lance mão dessas discussões em ambientes interessados em promover ensino que utilize prerrogativas neurocientíficas (p. 36). 
Diante das considerações anteriores sobre a importância das neurociências para a educação, no próximo item são abordadas suas particularidades e potencialidades.

\section{O ENCONTRO DA NEUROCIÊNCIA COGNITIVA E A ÁREA EDUCACIONAL: A NEUROEDUCAÇÃo}

A neuroeducação, enquanto área do conhecimento atingirá uma conexão de diferentes áreas, tornando-se um campo multidisciplinar. Percebe-se que a apropriação da aprendizagem, compreendida como modificação de comportamentos, é o que conecta as disciplinas desse saber. A possibilidade de a neuroeducação ser uma grande aliada da docência e de todo o contexto educacional conduz à ideia principal da neuroeducação.

Campos (2010) defende uma delimitação das áreas de saber para a sua interseção, mas, admite que a neuroeducação é caracterizada como uma nova abordagem de pensamento e ação. Essa área aponta como seu principal objetivo, oferecer aos educadores e professores conhecimentos que relacionam o cérebro à aprendizagem, levando em consideração as áreas de Pedagogia, Psicologia Cognitiva e as Neurociências.

Na mesma linha de conceituação, Tokuhama-Espinosa (2008) admite que a Neuroeducação tem a finalidade de abordar o conhecimento e a inteligência, integrando três áreas principais: a Psicologia, a Educação e as Neurociências e destaca o objetivo de explicar os comportamentos de aprendizagem. Um exemplo para isso, cita o autor, é a neuroeducação dar explicações sobre o papel das emoções no aprendizado, nos processos de tomada de decisão e nas várias possibilidades de motivação para o aprendizado pelos alunos. Uma esquematização possível do conceito é ilustrada na Figura 1. 
FIGURA 1 - Um conceito de Neuroeducação

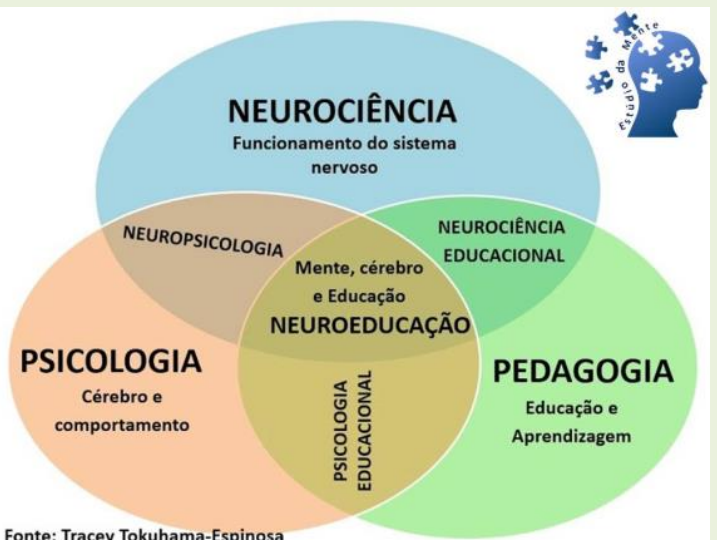

Fonte: http://meucerebro.com/o-surgimento-da-neuroeducacao/

Por meio dos estudos de Bartoszeck (2006) e Puebla e Talma (2011) é possível compreender como a literatura aponta $\bigcirc$ encontro das neurociências com a área educacional, considerando a aprendizagem construto comum a ambas. Ao descreverem o desenvolvimento da neuroeducação, conferem a esta nova ciência, não só a responsabilidade de investigar o processo de aprendizagem, mas também, de explicar diferentes níveis de complexidade neuronal envolvidos no processo.

Segundo Bartoszeck (2006), a neurociência investiga a especificidade de como o cérebro aprende e memoriza, processualmente, desde o nível molecular e celular até a ocorrência das sinapses nas áreas corticais, onde se dá a formação de padrões de atividade neural, correspondente a novos estados e representações mentais. Ou seja, a atividade de aprender é desencadeada de uma reação bioquímica e é realizada pela formação de memórias e conceitos pelo indivíduo.

Levando em consideração as aprendizagens escolares, Bartoszeck (2006) sugere que um ensino bem-sucedido é um fator provocado pela alteração na taxa de conexões sinápticas e pelo funcionamento da ordem cerebral. Esse conjunto de ideias leva a hipotetizar que em consequência dos estímulos sucedidos da atuação do professor, do método de ensino e do contexto da sala de aula e das organizações curriculares, ocorrem ou não as aprendizagens. 
Puebla e Talma (2011) apoiam-se na explicação do processamento da informação para a compreensão do encontro entre as neurociências e a área educacional. Fundamentados na analogia da aprendizagem humana que ocorre como o arquivamento de informações pelo computador, esses autores destacam a percepção, a memória, os simbolismos humanos e, sobretudo, a função executiva do cérebro como principais processos envolvidos nas conexões neuronais.

\section{O CÉREBRO E A COGNIÇÃO: aspectos para a formação de professores}

Para Silva e Morino (2012), os professores interessados pelo desenvolvimento de uma eficiente pedagogia tratarão de estudar componentes cerebrais de cunho anatômico e funcional, bem como psicólogos, neurocientistas buscarão relacionar as questões do cérebro com as habilidades necessárias para aprender os conteúdos escolares. Bartoszeck (2014) acredita numa "conversação produtiva entre o pesquisador em neurociências e o educador em geral" (p. 622).

Apesar de os fatores que determinam o desempenho dos estudantes serem de toda ordem, atualmente, os econômicos e sociais recebem especial atenção dos estudiosos da área educacional. Mas, sabe-se que os profissionais da educação que lidam com a maior parte das dificuldades em sala de aula têm levado em consideração os avanços científicos da neurociência cognitiva. Nesse sentido, é importante que os professores se apropriem do novo paradigma de saber que é a aprendizagem como produto do funcionamento cerebral (ANDRADE; PRADO, 2003; VIEIRA, 2012). Esse entendimento também é justificado por Bartoszeck (2014).

\footnotetext{
A aprendizagem no seu nível mais elementar, é um processo resultante de alterações neuro-anatômicas e neuroquímicas, semipermanentes ou permanentes na citoarquitetura cerebral. Por outro lado, a eficiência com a qual o cérebro 'aprende' a informação nova ou faz um ajuste na informação prévia, para adequar-se às novas circunstâncias ambientais, depende do grau de engajamento no contexto de aprendizagem em que se encontra o aprendiz (p. 613).
} 
Andrade e Prado (2003), em reconhecimento da expressiva importância dos conhecimentos neuro-funcionais para a pedagogia escolar, observam que "a compreensão do funcionamento do cérebro nos fornece fundamentos sólidos para a reformulação de metodologias de ensino" (p. 56). Para exemplificar essa afirmação, os autores prosseguem descrevendo o fenômeno da transferência de aprendizagem.

Por meio da observação em testes psicológicos e correspondentes neuronais, evidenciou-se que domínios cognitivos, relativamente independentes, podem ser transferidos, em maior ou menor grau, na medida em que as tarefas compartilham elementos neurológicos comuns. Relacionados a isso, estão os domínios espaço-temporais e visuo-espaciais presentes no processamento da aprendizagem musical, por exemplo, e que são transferidos para a aprendizagem de matemática. Os autores comentam ainda que "se ambas são processadas em áreas do cérebro envolvidas também no processamento visuo-espacial, parece bastante provável que o ensino de uma redundaria em benefício para o aprendizado da outra" (ANDRADE; PRADO, 2003, p. 5).

Em busca de discorrer sobre o ato de aprender à luz dos resultados das investigações das neurociências sobre o funcionamento do cérebro, ou seja, sobre as questões da aprendizagem na sua íntima relação com o substrato biológico do aluno, discorre-se a seguir sobre algumas funções cerebrais importantes para a área educacional, nos tópicos seguintes.

\section{Processamento humano da Informação}

As teorias cognitivas e as Neurociências, influenciadas pelo advento computacional e de um processamento de ordem digital, conceberam analisar os sistemas cognitivos dos seres humanos. Para descrever essa analogia de maneira sintética, articula-se que a informação - sinais sensoriais - chegam ao cérebro, são processadas por meio de uma operação de sistema de redes neuronais e se transformam em condutas e comportamentos (PUEBLA; TALMA, 2011). Esses autores conceituam que nesse processo 
[...] as redes criam determinado padrão conectivo, as quais cumulam a capacidade de retroalimentação devido à conecção com a memória, significando aprendizagem. Em outras palavras, após ocorrido determinado processamento de informação, ao apresentar a mesma configuração de conexões no sistema de redes neuronais no cérebro, diz-se que ocorreu uma aprendizagem. Após o período de aprendizado, quando você apresentar o mesmo padrão novamente para o sistema de rede, ele irá reconhecer e repetir a operação que já foi 'testada' anteriormente (PUEBLA; TALMA, 2011, p. 382. Tradução das autoras).

Em relação à diferença entre o processamento do sistema de redes neuronais e o processamento computacional, Puebla e Talma (2011) destacam uma característica importante que é a propriedade de auto ajuste ou auto-organização das redes do cérebro, que diferencia a mente humana dos computadores uma vez que tal característica confere a autonomia de "programação" que os computadores não têm.

\section{A atenção}

Manes (2015) argumenta que a função da atenção, na realização de uma tarefa, é dispor recursos para que o processamento da informação ocorra. A atenção está presente permanentemente nas ações e funções cerebrais de modo multifuncional nas funções seletiva, alternada e sustentada, principalmente na região dos lobos frontais.

De maneira seletiva, trata-se da habilidade de focalizar em determinada ideia ou tarefa para que distrações possam ser ignoradas, ou seja, é o principal tipo de atenção para evitar a perda de concentração na tarefa. A atenção alternada habilita a mudança do foco, ou seja, fornece a possibilidade de intercalar diferentes tarefas de níveis de exigência distintos. Em relação à atenção sustentada, trata-se da habilidade de manter uma resposta estável, durante uma atividade intensa ou repetitiva, possibilitando a concentração em uma tarefa por um período de tempo contínuo sem se distrair (MANES, 2015). 


\section{A memória}

De acordo com Silva e Morino (2012), "as memórias se formam quando um grupo de neurônios reage ao serem ativados" (p. 39). Izquierdo (2002) explica que a aprendizagem, em nível básico, pode ser vista como o processo para a aquisição da memória. Ela ocorre por processos neurológicos complexos que se traduzem em memória de longa duração ou consolidação.

\footnotetext{
Memória é a aquisição, a formação, a conservação e a evocação de informações. A aquisição é também chamada de aprendizado ou aprendizagem: só se 'grava' aquilo que foi aprendido. A evocação é também chamada de recordação, lembrança, recuperação. Só lembramos aquilo que gravamos, aquilo que foi aprendido (IZQUIERDO, 2002, p. 9).
}

Algumas estratégias de ensino, baseadas na neurociência, são de grande importância para o desenvolvimento das memórias semântica, episódica ou procedimental, automática e emocional. São atividades do tipo realizar perguntas, escrever resumos, parafrasear, repetir, entre outras (SILVA; MORINO, 2012).

\section{Sistemas cognitivos sociais}

São sistemas investigados pela neurociência cognitiva de especial interesse para o desenvolvimento da neuroeducação. São as atividades centradas nas áreas neocorticais que apresentam microcircuitos, mais complexos nos seres humanos, do que em outras espécies. A partir dessas localizações, distinguem-se importantes funções cerebrais relacionadas ao planejamento e controle das emoções e, em conjunto com outras regiões específicas do córtex temporal e junções têmporo-parietais, participam no processamento da linguagem verbal e da música. Portanto, é de fundamental importância que sejam conhecidas e estimuladas corretamente (ANDRADE; PRADO, 2003).

Muitas descobertas científicas sobre a mente humana se chocam com práticas pedagógicas tradicionais que vêm sendo desenvolvidas há anos e que não levam em consideração como o cérebro evoluiu e como 
está organizado nos seres humanos (NOGARO, 2012). A partir dessa recomendação, a presente investigação teve como objetivo levantar na literatura da área da Neurociência Cognitiva, conhecimentos teóricos da Neuroeducação para contextualizar e fundamentar as aplicações educacionais e pedagógicas de uma prática educativa. Para alcançar esse objetivo $O$ artigo se apoia nas pesquisas teóricas e empíricas encontradas e discute uma experiência que foi observada. A seguir relatase o percurso e desenvolvimento da pesquisa.

\section{A PRÁtICA PEDAGóGICA E A BUSCA DE FUNDAMENTOS NA NEUROEDUCAÇÃO Desenvolvimento}

Para o desenvolvimento do presente estudo, além do arcabouço teórico exposto na primeira parte do artigo, empreendeu-se a observação simples para a coleta de dados. Essa técnica foi escolhida com base na explicação de GIL (2008), que concebe a observação simples ou não participante útil ao conhecimento de situações de caráter público, para a apreensão da realidade de forma pouco sistemática. Compreende um caráter científico ao ser seguida de um processo de análise e interpretação, o que the confere certo controle requerido dos procedimentos científicos.

As práticas que são relatadas foram observadas em março de 2018 e descrevem um dia de aula e outras características pontuais da escola. Além da observação de um dia de atividades pedagógicas, as pesquisadoras acessaram documentos de orientações relacionados às atividades aplicadas; jogos e vídeos; e outros materiais de posse dos educadores da escola.

A educadora observada era estudante do último ano de pedagogia. A educadora realizou treinamentos teóricos e práticos para o uso dos materiais elaborados pela escola antes de ser admitida à função. A escola permitia que ela utilizasse materiais próprios e elaborados por ela mesma, desde que atendessem aos princípios de aprendizagem onde a prática aconteceu. 


\section{Participantes}

A escola onde se deu a observação é uma instituição de ensino não formal, franquiada de outras 300 unidades no Brasil, e que existe há pouco mais de 10 anos. Essa unidade está estabelecida há aproximadamente um ano, numa cidade do sul de Minas Gerais. Em geral, o seu público alvo são as pessoas a partir de cinco anos até a terceira idade. Com isso, as turmas são organizadas por objetivos de desenvolvimento, conforme interesse demonstrado pelo estudante no ato da matrícula.

Os objetivos mais requeridos pelos participantes, ao procurarem essa escola de Ensino não formal, são o desenvolvimento da concentração e o aprimoramento da capacidade de aprender. Observa-se que algumas habilidades mais procuradas são específicas de certos grupos etários, como por exemplo os adolescentes, que buscam sucesso no vestibular e que se interessam também por habilidades mentais que possam ajudar a ter um bom desempenho escolar.

Adultos procuram a escola para treinar habilidades do cérebro que possam ajudar em seu crescimento profissional e na manipulação das rotinas diárias, além de procurarem habilidades para evitação do estresse ou da fadiga mental. Pessoas da terceira idade apresentam como objetivos manter a mente saudável e a qualidade de vida por meio do treino de memória, mas também prezam pela evitação de doenças degenerativas do sistema nervoso como o Alzheimer.

A escola é procurada espontaneamente pelo público, devido ao fato de ser uma instituição particular. Em sua divulgação, afirma que seu diferencial é a metodologia ou programa pedagógico que pretende desenvolver um exercício cerebral, que seria responsável por atingir os objetivos de desenvolver atenção, concentração, foco, resiliência, memória, autodisciplina, raciocínio lógico, pensamento lateral, inteligência interpessoal e consequentemente, a autoestima (https://www.superaonline.com.br/).

A literatura respalda a possibilidade de instituições de ensino poderem oferecer condições de desenvolvimento desses aspectos que estão 
relacionados com aprendizagens e melhorias do estado psíquico. Fonseca (2015) respalda tais objetivos inferindo que:

Aprender a refletir, a raciocinar, a utilizar estratégias de resolução de problemas para adaptarmos as novas gerações a aprenderem mais, melhor e de forma diferente e flexível é uma necessidade fundamental da educação e, provavelmente a tarefa mais relevante da escola (p. 7).

\section{Materiais utilizados na escola}

A maioria do material que foi utilizado no dia da coleta de dados deste estudo faz referência ao manual pedagógico institucional ${ }^{3}$. Esse material é de utilização exclusiva dos educadores e são disponibilizados pela escola para a prática de sala de aula. Destaca-se que nem todos os materiais utilizados nas aulas estão disponíveis para a apreciação pública.

Na observação da aula, a educadora explicou sobre os materiais. É preconizada pela escola a utilização da maior variedade de materiais possível para a diversificação de desafios apresentados aos alunos. Essa diversificação deve primar pelo grau crescente do nível de dificuldade das tarefas.

Relatou-se também às pesquisadoras, que são consideradas como pilares para o sucesso da metodologia aplicada, seis ferramentas ${ }^{4}$. Dentre elas se destacam: o ábaco; os exercícios cognitivos; jogos; neuróbicas5; dinâmicas e o supera online. O ábaco (ou sorobã) é uma espécie de calculadora, de origem japonesa e que serve para o cálculo das quatro operações. O desígnio mental desse instrumento é desenvolver concentração (atenção focalizada), velocidade de raciocínio, perseverança e disciplina, habilidade motora fina e hábito de estudar.

Os exercícios cognitivos estão apostilados e contém atividades em formato de palavra cruzada, sudoku, jogo das diferenças, simetria,

3 O Manual Pedagógico Institucional é uma apostila não publicada para consulta do educador da escola com instruções, objetivos e modelos de atividades usadas com os alunos. A publicação tem os direitos reservados bem como a sua Marca SUPERAR.

${ }^{4}$ Linguagem adotada pela escola para nomear os recursos e atividades que o educador aplica aos alunos durante as aulas.

5 Termo utilizado pela escola para um conjunto de atividades. 
memorização, tangram, enigmas variados e de desafio crescente. Os jogos podem ser os comerciáveis ou produzidos pela educadora, desde que com eles as habilidades de memória, linguagem, raciocínio lógico, atenção sejam desenvolvidas ou mantidas.

Outras competências a serem desenvolvidas por meio de jogos são as chamadas competências socioemocionais que são ganhar, perder, respeitar o outro, respeitar limites e regras e pensamento estratégico. As neuróbicas são atividades que visam despertar conflito na zona de conforto cerebral. Explica-se que podem ser desenvolvidas estimulando-se os cinco sentidos por meio de exercícios. Um exemplo é realizar de forma diferente algo que é cotidiano, como mudar o caminho ou escovar os dentes com a mão oposta à dominante.

Em relação às dinâmicas, verificou-se que buscam oportunizar a interação grupal, a reflexão individual sobre si e sobre as interações com os outros. Com elas, a educadora crê oferecer a oportunidade de incorporar novos comportamentos sociais, desenvolver habilidades inter e intrapessoais, autoconfiança, capacidade de expressão e autoestima.

Por fim, a última ferramenta a ser comentada é o supera online, que é uma plataforma de jogos, oferecida aos alunos e educadores da escola em categorias criadas pelos desenvolvedores, por habilidades. Os jogos estão disponíveis para o desenvolvimento de atenção, linguagem, visão espacial, memória e raciocínio lógico. Uma vantagem de os jogos serem oferecidos online, para o aluno, é que o mesmo pode escolher a categoria e o nível que quer jogar. Para o educador, o registro da atuação de cada aluno no jogo é disponibilizado, permitindo que se use esses resultados para avaliar e acompanhar o desenvolvimento das metas de cada um e intervir sempre que necessário.

\section{O desenvolvimento da aula}

Em relação ao desenvolvimento, as aulas acontecem uma vez por semana, com duração de duas horas e turmas de, no máximo, 12 alunos. 0 
educador guia seu trabalho por temas mensais como, por exemplo, no dia da aula observada, "Uma aventura pelo cérebro".

De acordo com um tema, as semanas são organizadas em subtemas como "Funcionamento do Sistema Nervoso"; "Conhecendo os Neurônios", "Emoções e o cérebro" e "Sistema de Recompensa". A partir disso, tem-se um roteiro descrito pela escola para ser desenvolvido com os alunos.

Os participantes da aula, no dia da pesquisa, foram oito alunos, sendo cinco mulheres e três homens com a idade média de 46,7 anos, sendo que, todos eram adultos. Observou-se a recepção dos alunos, o início da aula e a orientação para que se organizassem nas carteiras. Logo que se acomodaram, sendo dada as boas vindas, a abertura da aula (essa parte da prática é chamada de conectando) teve a duração de 20 minutos. Nesse período, a educadora corrigiu atividades realizadas em casa e, em seguida, relembrou o tema do mês, apresentado em um vídeo intitulado "Emoções e o cérebro" com objetivo de refletir sobre o que são as emoções.

Logo após, sugeriu-se atividades que tinham por objetivo testar a capacidade de representar e identificar as emoções. Foi entregue a cada aluno um conjunto de placas, contendo imagens que sugeriam a ilustração de emoções como felicidade, tristeza, raiva, medo, nojo, susto e desprezo.

Num quadro, na lousa, a educadora marcava a opinião dada pelo aluno que era expressa levantando a placa, no momento pertinente. Para dar início ao jogo, foram embaralhadas as cartas e colocadas com as faces voltadas para baixo. Cada aluno, um de cada vez, tirava uma carta do monte e a representava com gestos e expressões faciais a todos, com 0 intuito de transmitir o que viu na carta que sorteou. Para isso, tinha um tempo de 30 segundos.

Durante a representação de quem sorteou a carta, os demais participantes tentavam identificar qual tinha sido sorteada pelo colega e se manifestavam erguendo uma placa para indicar a opinião deles sobre a representação. Todos os alunos participaram. As imagens do jogo estão ilustradas pela Figura 2. 
FIGURA 2 - Imagens de expressão de emoções

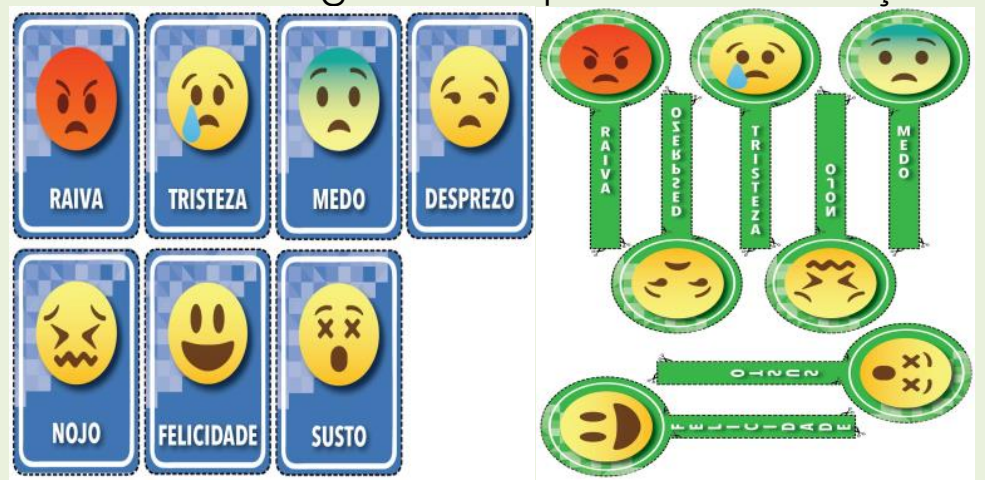

Fonte: Material pedagógico institucional.

Segue o excerto da fala de uma aluna, no momento do jogo, que pode ilustrar o efeito que surtiu para ela.

Expressar a emoção que estou sentindo no momento é mais fácil do que expressar uma que não estou sentindo, porque a minha foi nojo, mas eu não estou sentindo nojo de nada então é difícil. Mas quando estou com nojo de verdade percebem, na hora, a minha cara.

Na segunda parte da aula, foi realizada uma atividade com o ábaco, compreendendo um treino individual de aproximadamente 30 minutos e um ditado de operações. Essas atividades têm por objetivo trabalhar concentração e agilidade de raciocínio (MANUAL PEDAGÓGICO INSTITUCIONAL).

No treino individual, cada participante tem a própria meta e inicia consultando-a. Trata-se de uma meta estipulada com base na quantia de cálculos realizados no primeiro mês de atividades, depois é dividida pelo número de aulas do mês, para se saber qual será a meta semanal a ser atingida, a qual, deve sempre ser melhor que a média calculada. As atividades de cálculo são realizadas na apostila da escola.

No momento de treino de cálculos com sorobã, a educadora permanece acompanhando a realização dos exercícios e fazendo correções de postura, de manuseio do ábaco ou qualquer dificuldade apresentada, que possa requerer a sua ajuda. Após 25 minutos de treino individual, foi pedido que os alunos parassem os cálculos e fossem para a página de realização do ditado na apostila. 
As orientações para o ditado foram dadas pela educadora que solicitou que se perdessem alguma parte, não falassem nada e apenas parassem. Então, foram ditadas quatro operações em comum para todos os alunos. Em seguida, foram ditadas operações diferentes para os alunos, com diferentes graus de domínio do sorobã. Feita a correção pela educadora, os alunos anotaram a quantidade de acertos da atividade em suas fichas de progresso. Alguns comentários são apresentados a seguir: "Essa semana fiz mais porque durante as tarefas estava me autocorrigindo no manuseio"; "Mantive o mesmo desempenho da semana passada, porém minhas operações estão maiores nessa semana"; "Esta semana me desafiei a fazer 100 e consegui, estou muito feliz".

$\mathrm{Na}$ finalização do momento, a educadora explicou que utilizando o ábaco estavam trabalhando a atenção sustentada, que é uma habilidade de concentração em determinada tarefa, por um período contínuo sem se distrair. Ela enfatizou que essa habilidade poderia ajudá-los na realização de outras que necessitassem de atenção, como assistir uma palestra. Houve, então, um intervalo de 10 minutos.

Ao retornarem, outras atividades apostiladas da escola foram realizadas por um período de 30 minutos. Foram atividades de Sudoku, simetria, palavras cruzadas e Tangram. Para finalizar, anotaram resultados sobre seus progressos e apontaram verbalmente quais as que mais apreciaram realizar. Sobre isso a educadora comentou:

Provavelmente, essa preferência pode desencadear uma emoção positiva pela atividade, o que, provavelmente, impactará nos desempenhos. E da mesma forma que, se realizamos atividades no momento que não nos sentimos bem, pode haver a possibilidade de criarmos repugnância por ela.

Logo após, aconteceu o fechamento da aula desse dia. Para isso, a educadora entregou o desafio para a casa. Foi ainda exibido mais um vídeo intitulado "Emoções e a Neurociência" com a finalidade de promover o significado do tema da semana. 


\section{RESULTADOS E DISCUSSÃO}

O objetivo deste artigo foi levantar na literatura da área da Neurociência Cognitiva conhecimentos teóricos da Neuroeducação para contextualizar e fundamentar as aplicações educacionais e pedagógicas de uma prática educativa. De acordo com os autores que foram consultados e que dissertam sobre a Neurociência (HAEFFNER; GUIMARÃES, 2015; HASSE; PINHEIRO-CHAGAS; ARANTES, 2009; LEITE, 2011; MUSSAK, 1999; SILVA; MORINO, 2012) e a Neuroeducação (BARRIOS-TAO, 2016; BARTOSZECK, 2006; FONSECA, 2015; MIETTO, 2009; PUEBLA; TALMA, 2011; ZARO et al., 2010) verificou-se que é produtivo que, no campo educacional, as abordagens metodológicas possam se desenvolver a partir de modelos de aprendizagem e consequentes práticas que levem em consideração os processos cognitivos superiores.

Da mesma forma, verificou-se que os métodos e atividades de ensino devem buscar meios para o aprimoramento cognitivo, com vistas à potencialização dos desempenhos e resultados de aprendizagem, dando ênfase à importância de se conhecer aspectos da neurociência para embasar e melhorar a prática educativa. A literatura aponta, ainda, que os processos superiores (transferência; auto ajuste ou auto-organização das redes do cérebro; planejamento, atenção; memória e sistemas cognitivos sociais entre outros) são requeridos para a aprendizagem como condição para uma mente ativa e saudável para toda a vida.

Buscando articular os achados teóricos e os documentos das entrevistas iniciais dos estudantes da escola observada, verificou-se que os propósitos de aplicação e desenvolvimento funções cerebrais (memória, atenção, planejamento, emoções) coincidem, resultando que as pessoas comuns concordam com as pesquisas, em relação à importância de desenvolvimento das processos mentais superiores para o desenvolvimento e a manutenção cognitiva.

Os estudantes reconhem o valor de exercitar a mente e mantê-la ocupada e produtiva, como maneira de garantir melhor qualidade de vida cotidiana, além de buscar o incremento de habilidades mentais ainda pouco desenvolvidas. A escola por sua vez, afirma que objetiva aplicar o que está 
posto pela área neurocientífica, realizando nas aulas, estímulos ao cérebro (chamando de ginástica para o cérebro). Isso, por meio de materiais (ferramentas) que foram reunidos em apostilas, jogos, dinâmicas e atividades online, que os professores aplicam ou desenvolvem com os alunos depois de receberem formações específicas.

Cabe informar, que por ser um espaço de desenvolvimento e aprendizagem não formal, a escola participante desta pesquisa pode criar os currículos próprios e escolher temas (mensais e semanais) que podem estar centrados nas indicações neuroeducacionais como foco de trabalho. Isso não ocorre nas escolas de ensino regular, o que leva a considerar que esse tipo de metodologia ou atividade pedagógica, para ocorrer em larga escala, precisa fazer parte de currículos formais ou estar atrelada a conteúdos acadêmicos.

Os aspectos ligados à área de estudo das neurociências aplicados na educação podem ser considerados neuroeducacionais ou da neuroeducação. Buscando-se articular a neuroeducação às práticas observadas no presente estudo, podem ser citadas as atividades que foram aplicadas. Nelas, indicou-se o uso de atenção e concentração, treino e recuperação da memória, além da referência da educadora, ao uso de metas de superação pessoais, que podem ser consideradas, indicativos emocionais de aprendizagem. Esses elementos indicados pela literatura (PUEBLA; TALMA, 2011; SILVA MORINO, 2012; VIEIRA, 2012) como habilidades cerebrais foram levados em consideração para o desenvolvimento de redes neuronais.

Para Mietto (2009), a neurociência e consequentemente a neuroeducação dão aos professores subsídios para a elaboração de estratégias mais adequadas em cada caso de aprendizagem. O professor qualificado e capacitado, aliado a um método de ensino, são fundamentais para a efetiva estimulação das competências cerebrais alvo no aluno.

Em todo o tipo de escola em que se observa crianças e jovens com condições preocupantes de aprendizagem, é comum que os professores sejam culpabilizados pelas condições deles. Sobre isso, verificou-se que a escola pesquisada, ao se preocupar com a preparação dos seus educadores, investe na perspectiva de habilitar o educador a respeito de aspectos do 
funcionamento cerebral, para que os articulem as suas atividades e as práticas educacionais. Observou-se que existe a preocupação, por parte da escola e da educadora, de oferecer recursos selecionados para o desenvolvimento específico de necessidades, de acordo com as faixais etárias do público que a procura, conforme relato do início da descritiva da prática pedagógica.

Apesar de a educadora observada utilizar prioritariamente as atividades apostiladas, ela pode, por meio de suas arguições com os alunos, investir em suas abordagens de estudo, abrindo novos campos de aprendizado para eles e ser mais eficiente na transmissão do saber. Para Leite (2011), a Neuroeducação se desenvolve, principalmente, pela possibilidade de apresentar ferramentas capazes de corrigir dificuldades de aprendizagem escolar, transtornos de aprendizagem e ajudar no aprimoramento de crianças talentosas, além de prever instrumentos de inclusão social capazes de extrair o máximo do potencial funcional de cada indivíduo.

Ainda se descreve na literatura que é fundamental que o professor considere os sentimentos que impulsionam a aprendizagem positiva ou negativamente e ser capaz de perceber e entender as alegrias, tristezas, raivas, medos de seus alunos e principalmente ajudá-los a lidar adequadamente e de forma competente com as emoções (LEITE, 2011). A esse respeito disso, salienta-se que, na prática da educadora observada, houve um trabalho (atividades que tinham por objetivo testar a capacidade de representar e identificar as emoções - jogo com placas contendo imagens que sugerem emoções) em que se expôs vários comentários em conversa, com a intenção explícita de conscientização de sentimentos e emoções dos alunos. Constatase nessa prática, adotada para o mês e para a semana de aula uma relação da neuroeducação aplicada à prática da escola.

De acordo com o relato da observação e considerações da discussão do presente artigo, verificou-se a possibilidade de mostrar a articulação de aspectos da neuroeducação com as possibilidades da prática pedagógica ponderando que os objetivos do estudo foram alcançados. As práticas da escola observada mostraram indícios de coerência com o que a literatura, principalmente, no que tange à ênfase dada pelos autores citados no corpo

Revista Exitus, Santarém/PA, Vol. 9, N 3, p. 521 - 547, JUL/SET 2019. 
do texto, com respeito à importância de se conhecer aspectos da neurociência para embasar e melhorar a prática educativa. Algumas considerações sobre as fragilidades deste estudo podem ser verificadas no próximo item.

\section{CONSIDERAÇÕES FINAIS}

Considera-se como fragilidade do estudo a rápida observação realizada em campo para esta investigação que tratou de um único dia de aula de uma escola de ensino não formal. Apontamos que pesquisas posteriores poderão explorar mais dias de aula para obter-se uma visão mais ampla da prática pedagógica da escola.

Há ainda, a necessidade de aprofundamento em relação aos materiais utilizados pela escola (Ábaco, Tangran, Jogos de erros etc.) para verificação de sua validade, para ocasionarem estímulos de novas redes neuronais, bem como de treinarem a atenção e a memória no processamento humano da informação.

Em relação à busca de referencial teórico para o levantamento bibliográfico deste estudo considerou-se escassos os estudos que apontam as relações entre práticas pedagógicas e as descobertas neurocientíficas e neuroeducacionais. A falta de publicações a respeito do tema pode dificultar as análises empíricas de procedimentos e práticas de ensino relacionadas a situações de ganhos cognitivos.

Os artigos de pesquisa da área apontam mais as especulações sobre a necessidade de a Neuroeducação abranger as práticas educativas, do que as reais atuações e práticas de professores, na aplicação de conhecimentos da área. Os professores devem ser provocados a relatarem suas experiências práticas por meio de divulgações cinéticas. Nesse sentido é também essencial a atualização e extensão dos levantamentos bibliográficos no contexto da pesquisa educacional.

Em síntese, a área da Neuroeducação ainda é uma área em expansão, que necessita de aprofundamento de suas pesquisas e, principalmente, da formação de professores que saibam relatar as suas 
experiências, para que possa haver uma comparação de dados, o que garantiria muitas informações sobre a ciência em Neuroeducação e traria outros ganhos para a área educacional.

\section{REFERÊNCIAS}

ANDRADE; P. E.; PRADO; P. S. T. Psicologia e Neurociência cognitivas: Alguns avanços recentes e implicações para a educação. Interação em Psicologia, v. 2, n. 7, p. $73-80,2003$.

BARRIOS-TAO, H. Neurociências, educación y entorno sociocultural.

Educación y Educadores, v. 3, n. 19, p. 395-415, 2016. doi:

10.5294/vedu.2016.19.3.5

BARTOSZECK, A. B. Neurociência na educação. Revista Eletrônica

Faculdades Integradas Espírita, v. 1, p. 1-6, 2006. Disponível em:

http://docplayer.com.br/1245408-Neurociencia-na-educacao-a-bbartoszeck.html Acesso em: 02 de abril de 2018.

BARTOSZECK, A. B. Neurociências, Altas Habilidades e implicações no currículo. Revista Educação Especial, v. 27, n. 50, p. 611-626, Santa Maria, 2014. Disponível em: <http://www.ufsm.br/revistaeducacaoespecial> Acesso em: 02 de abril de 2018. doi.10.5902/1984686X14284

CAMPOS, A. L. Neuroeducación: uniendo las neurociências y la educación en la búsqueda del desarollo humano. La Educ@ción, n. 143, 2010. Disponível em:

http://www.educoea.org/portal/La_Educacion_Digital/laeducacion_143/arti cles/ne uroeducacion.pdf. Acesso em: 11 de novembro de 2018.

FLAVELL, J. H. Cognitive development: Children's knowledge about the mind. Annual Review of Psychology, n. 50, p. 21-45. 1999.

FONSECA, V. Cognição, neuropsicologia e aprendizagem: abordagem neuropsicológica e psicopedagógica. 7. ed., Petrópolis, RJ: Vozes, 2015.

GIL, A. C. Métodos e técnicas de pesquisa social. 6. ed. São Paulo: Atlas, 2008.

HAASE, V. G.; PINHEIRO-CHAGAS, P.; ARANTES, É. A. Um Convite à Neurociência Cognitiva Social. Gerais: Revista Interinstitucional de Psicologia, v. 1, n. 2, p. 43-49, 2009.

HAEFFNER, C.; GUIMARÃES, J. A. Produção científica indexada na base Web of Science na área de Neurociências e Comportamento relacionada com o tema Educação. RBPG, Brasília, v. 12, n. 29, p. 773-801, 2015.

IZQUIERDO, I. Memória, Porto Alegre: Artmed 2002. 
LEITE, S. F. B. S. C. Neurociência: um novo olhar educacional. n. 17, 2011. Não paginado. Disponível em:

https://www.webartigos.com/artigos/neurociencia-um-novo-olhareducacional/63961/. Acesso em: 12 abr. 2018.

LEME, M. I. S. As especificidades humanas e a aprendizagem: relações entre cognição, afeto e cultura. Psicologia USP, São Paulo, v. 4, n. 22, p. 703-723, 2011.

MANES, F. Usar o cérebro: Aprenda utilizar a máquina mais complexa do universo. Tradução Olga Cafalchio. São Paulo: Planeta, 2015.

MIETTO, V. L. A importância da neurociência na educação. 31 dez. 2009. Disponível em:

http://pedagogia.com.br/artigos/neurocienciaaeducacao/index.php?pagin $\mathrm{a}=0$. Acesso em: $12 \mathrm{abr} .2018$.

MUSSAK, E. C. Cérebro de estudante: e você sempre será um. Campinas, SP: Gráfica e Editora Paes, 1999.

NOGARO, A. Neurociência formação de professores e práticas pedagógicas. 12 jun. 2012. Disponível em:

https://www.webartigos.com/artigos/neurociencia-formacao-de-professorese-praticas-pedagogicas/901 18/. Acesso em: 22 fev. 2018.

PIAGET, J. Biologia e conhecimento: ensaio sobre as relações entre as regulações orgânicas e os processos cognoscitivos. Petrópolis: Vozes, 1973.

PUEBLA, R.; TALMA M. P. Educación y neurociencias. La conexión que hace falta. Estúdios Pedagógicos, v. 34, n. 2, p. 379 - 388, 2011.

SILVA, F.; MORINO, C. R. I. A importância das neurociências na formação de professores. Momento, Rio Grande. v. 21, n. 1, p. 29 - 50, 2012. Disponível em: https://www.seer.furg.br/momento/article/view/2478. Acesso em: 22 fev. 2018.

TOKUHAMA-ESPINOSA, T. N. The scientifically substantiated art of teaching: a study in the development of standards in the new academic field of neuroeducation (mind, brain, and education science). 2008. 611 p. Tese (Doutorado em Educação) Capella University, Mineápolis, Minesota. 2008. Disponível em:

https://pqdtopen.proquest.com/doc/250881375.htmlaFMT=ABS. Acesso em: 11 se novembro de 2018.

VIEIRA, E. P. P. Neurociências, Cognição e Educação: Limites e Possibilidades na Formação de Professores. REVISTA PRÁXIS, v. 4, n. 8., p. 31 - 38, 2012.

ZARO, M. A. et al. Emergência da Neuroeducação: a hora e a vez da neurociência para agregar valor à pesquisa educacional. Ciências \& 
Cognição, v. 15, n. 1, p. 199 - 210, 2010. Disponível em

http://www.cienciasecognicao.org. Acesso em: 02 de maio de 2018.

Recebido em: 03 de agosto de 2018.

Aprovado em: 10 de abril de 2019. 